\title{
Candida bracarensis sp. nov., a novel anamorphic yeast species phenotypically similar to Candida glabrata
}

\author{
Correspondence \\ Célia Pais \\ cpais@bio.uminho.pt
}

\author{
Alexandra Correia, ${ }^{1}$ Paula Sampaio, ${ }^{1}$ Steve James $^{2}$ and Célia Pais ${ }^{1}$ \\ ${ }^{1}$ Centro de Biologia da Universidade do Minho (CBUM), Departamento de Biologia, Campus de \\ Gualtar, 4710-057 Braga, Portugal \\ ${ }^{2}$ National Collection of Yeast Cultures, Institute of Food Research, Norwich Research Park, \\ Colney, Norwich NR4 7UA, UK
}

The genus Candida belongs to the ascomycetous yeasts and includes some of the most common human pathogens [e.g. Candida albicans and Candida tropicalis (Ahearn, 1998)]. About 20 species of Candida have been shown to cause disease in humans, but the list of medically important yeasts continues to grow, mostly due to developments in medical interventions and to the increasing number of immunodeficient patients. Improved molecular methods for detecting and differentiating yeasts are also able to distinguish closely related species, providing evidence for the existence of new Candida species (e.g. Candida dubliniensis, Candida orthopsilosis) previously misidentified by conventional chemotaxonomic criteria and which may represent new emerging pathogens (Sullivan et al., 1995; Tavanti et al., 2005).

Following an epidemiological study of candidiasis in the north of Portugal (Correia et al., 2004), one of the clinical isolates (strain $153 \mathrm{M}^{\mathrm{T}}$ ), identified originally as Candida glabrata, was found to have a different and quite unique

Published online ahead of print on 13 October 2005 as DOI 10.1099/ ijs.0.64076-0.

\footnotetext{
Abbreviation: ITS, internal transcribed spacer.

The GenBank/EMBL/DDBJ accession number for the 26S rDNA D1/D2 domain and complete ITS and 5.8S rDNA gene sequences of Candida bracarensis $153 \mathrm{M}^{\top}$ are AY589572 and AY589573, respectively.

A figure showing the pairwise alignment of the 26S rDNA D1/D2 sequences of C. glabrata, $K$. delphensis and strain $153 \mathrm{M}^{\top}$ is available as supplementary material in IJSEM Online.
}

T3B fingerprinting pattern. In order to clarify its taxonomic position, conventional physiological and biochemical characterization (Yarrow, 1998) as well as rDNA sequencing was performed. A search for similar sequences in the GenBank sequence database revealed the existence of a second strain [NCYC 3133 (formerly NCYC D3411)], isolated from a patient in a UK hospital, with high sequence similarity in the $26 \mathrm{~S}$ rDNA D1/D2 region. The two clinical isolates shared identical physiological and molecular characteristics and were related to C. glabrata, a species of growing medical concern (Fidel et al., 1999), and to Kluyveromyces delphensis [recently renamed Nakaseomyces delphensis (Kurtzman, 2003)]. However, the extent of sequence divergence was large enough to propose the assignment of these isolates to a novel species, described in this paper as Candida bracarensis sp. nov.

\section{Yeast isolates and their characterization}

The strains under study were isolated from patients suffering from candidiasis. Strain $153 \mathrm{M}^{\mathrm{T}}$ was collected from a vaginal exudate in a Portuguese hospital and strain NCYC 3133 was isolated from a blood culture from a UK hospital.

The isolates were characterized by using standard chemotaxonomic methods (Yarrow, 1998) and by PCR fingerprinting with primer T3B (Correia et al., 2004).

\section{rDNA sequencing and sequence analysis}

The D1/D2 domain of the 26S rDNA was amplified and sequenced according to the procedures described by 
Sampaio et al. (2001). The entire ribosomal internal transcribed spacer (ITS) region, including the $5 \cdot 8 \mathrm{~S}$ rDNA, was amplified using the forward primer ITS1 ( $5^{\prime}$-TCCGTAGGTGAACCTGCGG- $3^{\prime}$ ) and reverse primer ITS4 (5' - TCCTCCGCTTATTGATATGC- $3^{\prime}$ ) and sequenced using the amplification primers (ITS1 and ITS4) as well as two additional internal primers, ITS2 (5'-GCTGCGTTCTTCATCGATGC- $3^{\prime}$ ) and ITS3 (5'-GCATCGATGAAGAACGCAGC- ${ }^{\prime}$ ) (White et al., 1990). In the case of NCYC 3133, PCR amplification of both rDNA regions was carried out directly from whole yeast cells using the protocol described by James et al. (2005). Sequencing was performed with an ABI 310 Genetic Analyzer (Applied Biosystems) using standard protocols. Forward and reverse sequence alignments were made with MegAlign (DNASTAR) and corrected visually.

The 26S rDNA D1/D2 sequences determined in this study were compared with sequences from the GenBank database and aligned with CLUSTAL_X version 1.81 (Thompson et al., 1997). Phylogenetic analysis was carried out using the PAUP* version $4.0 \mathrm{~b} 8$ software package (Swofford, 2000) and the $26 \mathrm{~S}$ rDNA D1/D2-derived tree was constructed by using the neighbour-joining method (Saitou \& Nei, 1987) with the Kimura two-parameter distance measure. Confidence limits were estimated from bootstrap analysis (1000 replicates) and only values of $50 \%$ or greater were recorded on the tree.

\section{Molecular fingerprinting profiles}

When analysed by PCR fingerprinting using primer T3B, strains $153 \mathrm{M}^{\mathrm{T}}$ and NCYC 3133 were found to have very similar profiles which were quite distinct from those of $C$. glabrata and $K$. delphensis strains (Fig. 1).

\section{Physiological and biochemical characterization}

The physiological and biochemical characteristics of strains $153 \mathrm{M}^{\mathrm{T}}$ and NCYC 3133 were found to be similar, but not identical, to those of C. glabrata and K. delphensis. In fact, the two strains can be separated from C. glabrata, their nearest known relative (Fig. 2), on the basis of L-lysine assimilation. Both novel strains are able to utilize L-lysine as a sole nitrogen source, whereas strains of C. glabrata assimilate this compound either weakly or not at all (Barnett et al., 2000; Meyer et al., 1998). Similarly, strains $153 \mathrm{M}^{\mathrm{T}}$ and NCYC 3133 can be readily separated from $K$. delphensis based on their ability to assimilate both L-lysine and $\alpha, \alpha$-trehalose, to ferment $\alpha, \alpha$-trehalose, to grow at temperatures in excess of $40^{\circ} \mathrm{C}$ and by an inability to assimilate ethanol (Barnett et al., 2000; Lachance, 1998).

\section{Phylogenetic analysis}

Sequence analysis of the D1/D2 domain of 26S rDNA for strain $153 \mathrm{M}^{\mathrm{T}}$ showed the highest similarity with strain NCYC 3133 (differing by a single nucleotide substitution). Strain Candida cf. glabrata UWO(PS)98-110.4 and three clinical strains, designated JAF-2004 isolates 2960 to 2962, also shared a high similarity with strain $153 \mathrm{M}^{\mathrm{T}}$, showing 14

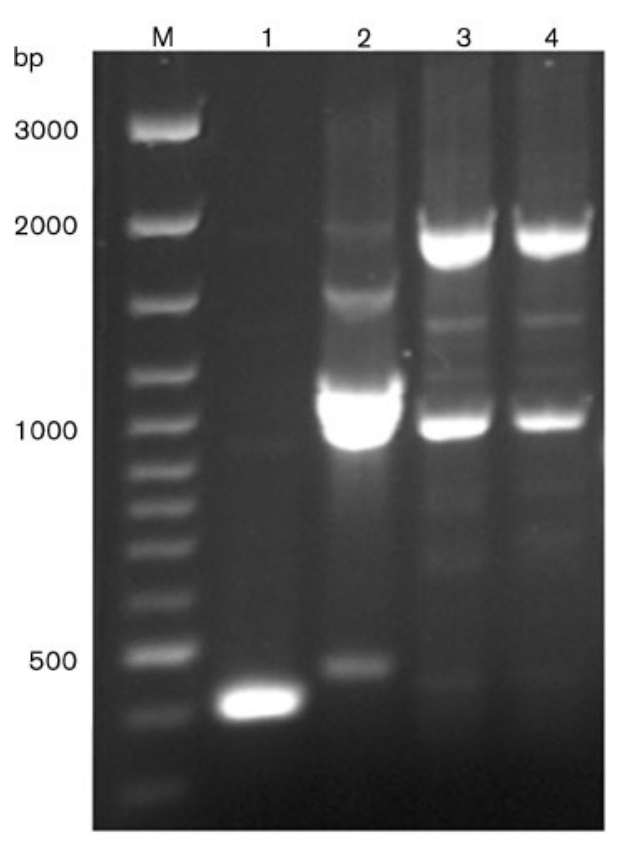

Fig. 1. PCR profiles obtained with primer T3B. Lanes: $1, C$. glabrata CBS $138^{\top} ; 2$, Kluyveromyces delphensis PYCC 2899; 3 , strain $153 \mathrm{M}^{\top} ; 4$, strain NCYC 3133. M, Molecular size marker.

nucleotide differences and 14 nucleotide substitutions and two gaps, respectively. Analysis of the phylogenetic tree derived from the alignment of D1/D2 sequences showed that the two closest species to strains $153 \mathrm{M}^{\mathrm{T}}$ and NCYC 3133 were C. glabrata and K. delphensis (Fig. 2). Sequence similarity values were estimated from an alignment of the D1/D2 sequences of the respective type strains with strain $153 \mathrm{M}^{\mathrm{T}}$. The similarity between $C$. glabrata and $K$. delphensis was $92 \%$, corresponding to 38 nucleotide differences and four gaps. When compared with these species, strain $153 \mathrm{M}^{\mathrm{T}}$ displayed $94 \cdot 8 \%$ sequence similarity with C. glabrata (corresponding to 30 nucleotide differences) and $93.8 \%$ similarity with $K$. delphensis (corresponding to 32 nucleotide differences and four gaps). The pairwise alignment of $26 \mathrm{~S}$ rDNA D1/D2 sequences is presented in Supplementary Fig. S1 available in IJSEM Online).

Sequence analysis was also carried out on the entire ribosomal ITS region (i.e. ITS1/5.8S rDNA/ITS2) of strains $153 \mathrm{M}^{\mathrm{T}}$ and NCYC 3133 . Both strains were found to have ITS1 sequences of identical length (305 bp), which differed from one another by a total of 13 base substitutions, corresponding to $95.7 \%$ sequence similarity. Likewise, the ITS2 sequences of the two novel strains were found to be $252 \mathrm{bp}\left(153 \mathrm{M}^{\mathrm{T}}\right)$ and $253 \mathrm{bp}$ (NCYC 3133) in length and differed from one another by a single base substitution and a single nucleotide gap $(99 \cdot 2 \%$ sequence similarity). Such levels of ITS1 and ITS2 sequence divergence probably reflect the fact that the strains were isolated from patients in separate hospitals, one in Portugal $\left(153 \mathrm{M}^{\mathrm{T}}\right)$ and the other in the UK (NCYC 3133). Comparison of the complete ITS 


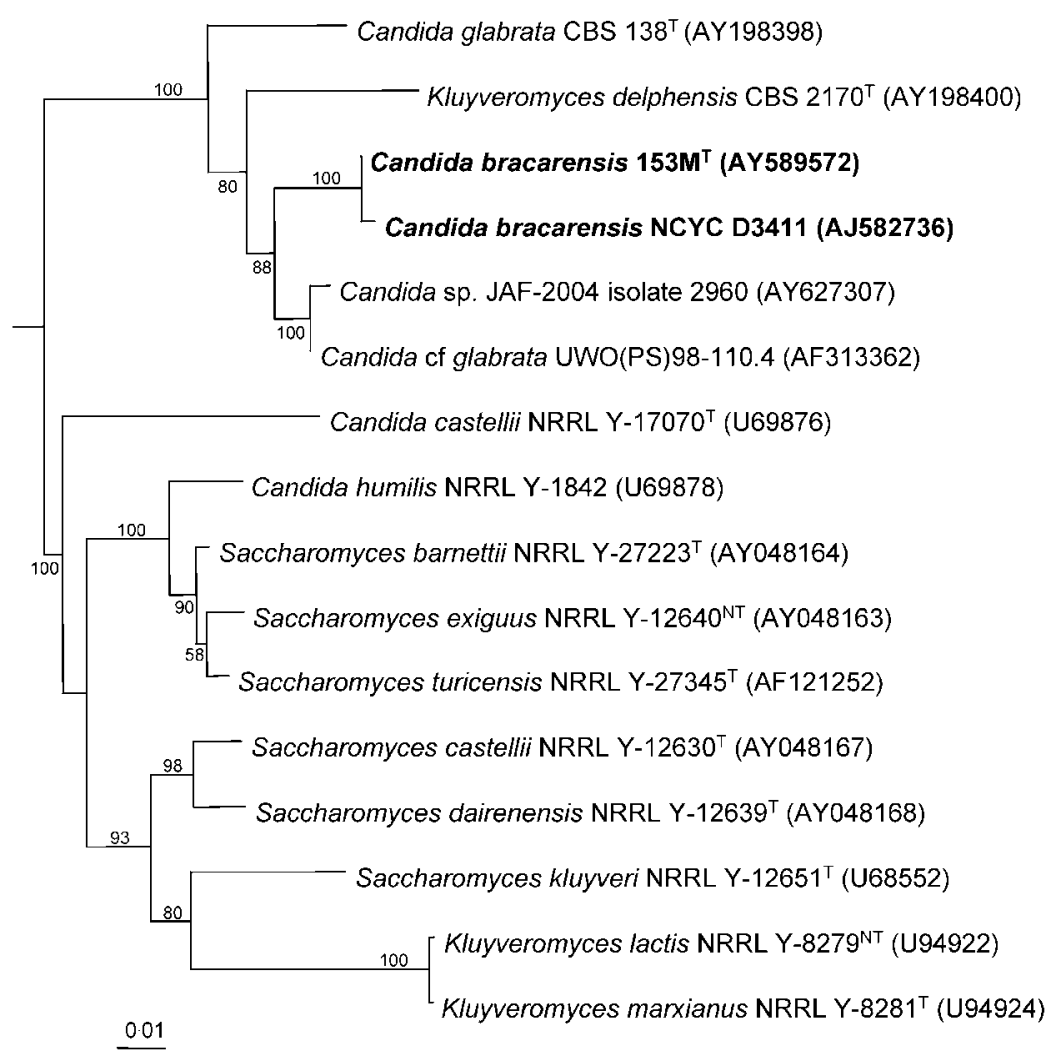

Fig. 2. Phylogenetic tree derived from neighbour-joining analysis based on $26 S$ rDNA D1/D2 region sequences showing the placement of Candida bracarensis sp. nov. and its closest relatives. Only bootstrap percentages (1000 replicates) of $50 \%$ or greater are shown. Bar, $1 \%$ nucleotide sequence divergence. sequences revealed that $153 \mathrm{M}^{\mathrm{T}}$ displayed greater sequence similarity to K. delphensis (68\%) than to C. glabrata (65\%), while $153 \mathrm{M}^{\mathrm{T}}$ and NCYC 3133 displayed $97.9 \%$ sequence similarity to each other.

Despite being related to C. glabrata, the number of nucleotide substitutions in the D1/D2 region (30 nucleotides over 581 ) of the novel strains is much higher than the $0-3$ nucleotide differences typically observed between either conspecific or sister species (Kurtzman \& Robnett, 1997, 1998). Indeed, as the $26 \mathrm{~S}$ rDNA D1/D2-derived tree in Fig. 2 illustrates, strains $153 \mathrm{M}^{\mathrm{T}}$ and NCYC 3133 clearly belong to a phylogenetically distinct species, a fact supported by both ITS sequencing and PCR fingerprint profiling. Consequently, based on the collective results of this study, a novel species, Candida bracarensis sp. nov., is proposed. As the novel species exhibited an API 32C profile identical to C. glabrata, it seems possible that $153 \mathrm{M}^{\mathrm{T}}$ and NCYC 3133 may not be unique isolates of this species and similar clinical isolates may well exist, but may have been misidentified as C. glabrata.

This novel species adds to the overall knowledge of yeast biodiversity and represents an additional reference in its phylogenetic clade. This is particularly significant for yeast groups impacting on human health, since modern medical therapy and improved methods for detecting and differentiating yeasts have shown that many novel and unusual species have become clinically important.

\section{Latin diagnosis of Candida bracarensis Correia, Sampaio, James et Pais sp. nov.}

In medio liquido malti post dies tres ad $30^{\circ} \mathrm{C}$, cellulae sunt globosae $(3 \cdot 0-3 \cdot 5 \mu \mathrm{m})$ ad ellipsoideae $(3 \cdot 0-4 \cdot 0 \times 4 \cdot 0-4 \cdot 5$ $\mu \mathrm{m})$ singulae aut binae (Fig. 3 ). In agaro malti post 7 dies ad $30{ }^{\circ} \mathrm{C}$, cultura albida cremea, centrum colonia altum, butyrosa et margine glabro. In agaro farinae Zea mays post dies 21 ad $25^{\circ} \mathrm{C}$, pseudohyphae et hyphae verae absentes. Asci non formantur. Glucosum et trehalosum fermentantur. Galactosum, maltosum, sucrosum, lactosum, cellobiosum, melezitosum, raffinosum et inulunum non fermentantur. Assimilantur glucosum, trehalosum, glycerolum, D-glucono-1,5-lactonum, D-gluconatum et L-lysinum. Non assimilantur galactosum, L-sorbosum, sucrosum, maltosum, cellobiosum, melezitosum, D-xylosum, L-arabinosum, D-arabinosum, D-ribosum, Dglucosaminum, ethanolum, erythritolum, ribitolum, xylitolum, D-mannitolum, D-glucitolum, methyl- $\alpha$-D-glucosidum, salicinum, acidum lacticum, arbutinum, acidum succinicum, acidum citricum, lactosum, inulinum, raffinosum, melibiosum, amylum solubile, L-rhamnosum, methanolum, galactitolum, D-glucuronatum, cadaverinum, ethylaminum, Dglucosaminum (nitrogenium), imidazolum, creatinum, creatininum, kalium nitratum, natrium nitritum et Dtryptophanum. Temperatura $42^{\circ} \mathrm{C}$ crescit. Materia amyloidea et acidum aceticum non formantur. Diazonium coerulaeum B negativum.

Typus CBS $10154^{\mathrm{T}}$ isolatus ex vaginae. Depositus et 


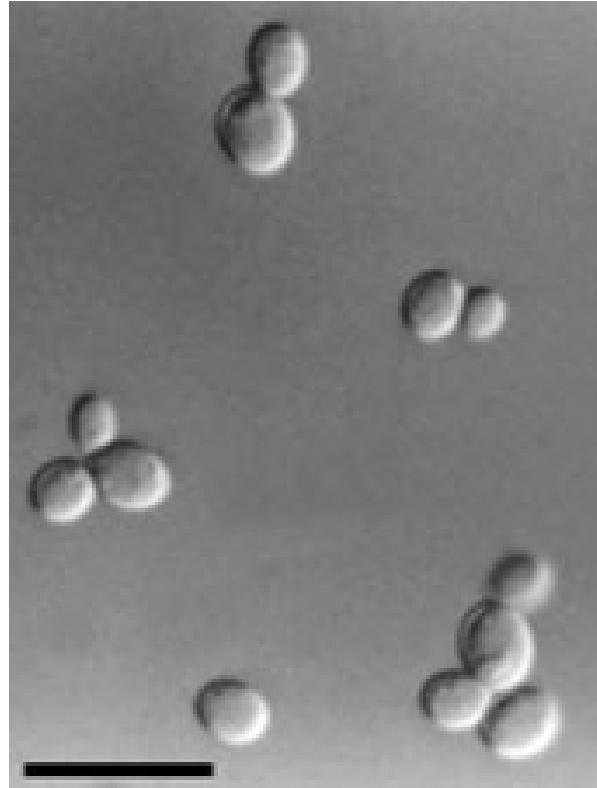

Fig. 3. Differential interference contrast micrograph of Candida bracarensis $153 \mathrm{M}^{\top}$ cells grown in $\mathrm{YM}$ broth after 3 days at $30^{\circ} \mathrm{C}$. Bar, $10 \mu \mathrm{m}$.

preservatus in Collectione Zymotica Centraalbureau voor Schimmelcultures Culturarum, Utrecht.

\section{Description of Candida bracarensis Correia, Sampaio, James \& Pais sp. nov.}

Candida bracarensis [brac'ar.en.sis. L. fem. adj. bracarensis pertaining to Bracara Augusta, the roman name of the city (Braga, Portugal) from where the type strain was isolated.]

In YM broth, after 3 days at $30^{\circ} \mathrm{C}$, the cells are spherical $(3 \cdot 0-3 \cdot 5 \mu \mathrm{m})$ to ellipsoidal $(3 \cdot 0-4 \cdot 0 \times 4 \cdot 0-4 \cdot 5 \mu \mathrm{m})$ and occur singly or in pairs (Fig. 3). On YM agar, culture colonies are umbonate, pale cream, glistening and butyrous with an entire margin. Neither pseudohyphae nor true hyphae are formed under the coverglass in Dalmau plate culture on cornmeal agar after 21 days at $25^{\circ} \mathrm{C}$. Ascospores are not detected in the type strain when grown for up 3 months on YM agar or sodium acetate agar incubated at $25^{\circ} \mathrm{C}$. Glucose and $\alpha, \alpha$-trehalose are fermented. Carbon compounds sucrose, $\alpha, \alpha$-trehalose, glycerol, D-glucono1,5-lactone and D-gluconate are assimilated. No growth occurs on D-galactose, L-sorbose, D-glucosamine, D-ribose, D-xylose, D-arabinose, L-arabinose, L-rhamnose, maltose, methyl $\alpha$-D-glucoside, cellobiose, arbutin, salicin, melibiose, lactose, raffinose, melezitose, inulin, starch, erythritol, ribitol, xylitol, D-glucitol, D-mannitol, galactitol, D-glucuronate, DL-lactate, succinate, citrate, methanol or ethanol. The only nitrogen compound assimilated is L-lysine. Tests for the Diazonium blue B reaction, urea hydrolysis and starch and acetic acid formation are negative. Growth occurs on $0 \cdot 1 \%$ cycloheximide and at $42{ }^{\circ} \mathrm{C}$.

The type strain, $153 \mathrm{M}^{\mathrm{T}}\left(\mathrm{CBS} 10154^{\mathrm{T}}=\mathrm{CECT} 12000^{\mathrm{T}}=\right.$ NCYC D3853 $3^{\mathrm{T}}$ ), was isolated from a case of vaginal candidiasis in a medical institution, Braga, Portugal.

\section{Acknowledgements}

This research was supported by Fundação para a Ciência e Tecnologia (FCT) through a multi-year contract with Centro de Biologia da Universidade do Minho (CB-UM). Magda Graça is gratefully acknowledged for operating the nucleic acid sequencer. We thank Marc-André Lachance for critical comments and helpful suggestions.

\section{References}

Ahearn, D. G. (1998). Yeasts pathogenic for humans. In The Yeasts: $a$ Taxonomic Study, 4th edn, pp. 9-12. Edited by C. P. Kurtzman \& J. W. Fell. Amsterdam: Elsevier.

Barnett, J. A., Payne, R. W. \& Yarrow, D. (2000). Yeasts: Characteristics and Identification, 3rd edn. Cambridge: Cambridge University Press.

Correia, A., Sampaio, P., Almeida, J. \& Pais, C. (2004). Study of molecular epidemiology of candidiasis in Portugal by PCR fingerprinting of Candida clinical isolates. J Clin Microbiol 42, 5899-5903.

Fidel, P. L., Jr, Vazquez, J. A. \& Sobel, J. D. (1999). Candida glabrata: review of epidemiology, pathogenesis, and clinical disease with comparison to C. albicans. Clin Microbiol Rev 12, 80-96.

James, S. A., Bond, C. J., Stratford, M. \& Roberts, I. N. (2005). Molecular evidence for the existence of natural hybrids in the genus Zygosaccharomyces. FEMS Yeast Res 5, 747-755.

Kurtzman, C. P. (2003). Phylogenetic circumscription of Saccharomyces, Kluyveromyces and other members of the Saccharomycetaceae, and the proposal of the new genera Lachancea, Nakaseomyces, Naumovia, Vanderwaltozyma and Zygotorulaspora. FEMS Yeast Res 4, 233-245.

Kurtzman, C. P. \& Robnett, C. J. (1997). Identification of clinically important ascomycetous yeasts based on nucleotide divergence in the $5^{\prime}$ end of the large-subunit (26S) ribosomal DNA gene. J Clin Microbiol 35, 1216-1223.

Kurtzman, C. P. \& Robnett, C. J. (1998). Identification and phylogeny of ascomycetous yeasts from analysis of nuclear large subunit (26S) ribosomal DNA partial sequences. Antonie van Leeuwenhoek 73, 331-371.

Lachance, M. A. (1998). Kluyveromyces van der Walt emend. Van der Walt. In The Yeasts: a Taxonomic Study, 4th edn, pp. 227-247. Edited by C. P. Kurtzman \& J. W. Fell. Amsterdam: Elsevier.

Meyer, S. A., Payne, R. W. \& Yarrow, D. (1998). Candida Berkhout. In The Yeasts: a Taxonomic Study, 4th edn, pp. 454-573. Edited by C. P. Kurtzman \& J. W. Fell. Amsterdam: Elsevier.

Saitou, N. \& Nei, M. (1987). The neighbor-joining method: a new method for reconstructing phylogenetic trees. Mol Biol Evol 4, 406-425.

Sampaio, J. P., Gadanho, M., Santos, S., Duarte, F. L., Pais, C., Fonseca, A. \& Fell, J. W. (2001). Polyphasic taxonomy of the basidiomycetous yeast genus Rhodosporidium: Rhodosporidium kratochvilovae and related anamorphic species. Int J Syst Evol Microbiol 51, 687-697.

Sullivan, D. J., Westerneng, T. J., Haynes, K. A., Bennett, D. E. \& Coleman, D. C. (1995). Candida dubliniensis sp. nov.: phenotypic 
and molecular characterization of a novel species associated with oral candidosis in HIV-infected individuals. Microbiology 141, 1507-1521.

Swofford, D. L. (2000). PAUP*: Phylogenetic analysis using parsimony (* and other methods). Sunderland, MA: Sinauer Associates.

Tavanti, A., Davidson, A. D., Gow, N. A. R., Maiden, M. C. J. \& Odds, F. C. (2005). Candida orthopsilosis and Candida metapsilosis spp. nov. to replace Candida parapsilosis groups II and III. J Clin Microbiol 43, 284-292.

Thompson, J. D., Gibson, T. J., Plewniak, F., Jeanmougin, F. \&

Higgins, D. G. (1997). The CLUSTAL_X windows interface: flexible strategies for multiple sequence alignment aided by quality analysis tools. Nucleic Acids Res 25, 4876-4882.

White, T. J., Bruns, T., Lee, S. \& Taylor, J. (1990). Amplification and direct sequencing of fungal ribosomal RNA genes for phylogenetics. In PCR Protocols: a Guide for Methods and Applications, pp. 315-322. Edited by M. A. Innis, D. H. Gelfand, J. J. Sninsky \& T. J. Taylor. New York: Academic Press.

Yarrow, D. (1998). Methods for the isolation, maintenance, classification and identification of yeasts. In The Yeasts: a Taxonomic Study, 4th edn, pp. 77-100. Edited by C. P. Kurtzman \& J. W. Fell. Amsterdam: Elsevier. 